\title{
Tubulointerstitial Nephritis and Uveitis (TINU) Syndrome, Two New Cases and Review of the Literature
}

\author{
A Laidoudi ${ }^{*}$, D Hakem ${ }^{1}$, A Ghout $^{1}$, A Boukrara ${ }^{1}$, S Medaoud $^{1}$, A Boudjelida $^{1}$, M Salah $^{1}$, D Boulfani ${ }^{1}$, F Haddoum $^{2}$, Djenane $^{3}, \mathrm{~K} \mathrm{Kalem}^{4}$ and A Berrah $^{1}$ \\ ${ }^{1}$ Internal Medecine Department, Mohammad-Lamine-Debaghine Hospital, Algeria \\ ${ }^{2}$ Nephrology Department, Nafissa Hamoud Hospital, Algeria \\ ${ }^{3}$ Anatomopathology Department, Mohammad-Lamine-Debaghine Hospital, Algeria \\ ${ }^{4}$ Anatomopathology Department, Nafissa Hamoud Hospital, Algeria
}

"Corresponding author: Aicha Laidoudi, Mohamed Lamine Debaghine Hospital, Internal Medicine, Boulevard Said Touati, Bab El Oued Alger, Algiers, Algeria, Tel: +213666369560; Fax: +213558273957; E-mail: mailto:aic.laid@gmail.com

Received date: June 7, 2016; Accepted date: June 16, 2016; Publication date: June 22, 2016

Copyright: ( 2016 Laidoudi A, et al. This is an open-access article distributed under the terms of the Creative Commons Attribution License; which permits unrestricted use; distribution; and reproduction in any medium; provided the original author and source are credited.

\begin{abstract}
Case 1: A 25 year-old woman, presented with asthenia; weight loss; severe hypertension and acute unilateral anterior uveitis. She had also proteinuria; hematuria; aciduria; kidney failure and grade I hypertensive retinopathy. Kidney biopsy showed a non caseating granuloma in the interstitial tissue, and tubulointerstitial nephritis (TIN) with granulomatous lesions in the medullary parenchyma. All explorations were negative but QuantiFERON was 10 times normal without koch's bacillus. No other sites of granulomas. The patient partially responded to corticoid treatment. She replased after untimely stopping corticosteroids. Corticosteroid-sparing was provided by mycophenolate mofetil.
\end{abstract}

Case 2: A 46 year-old patient, with family history of mother who died of CKD, presented with recurrent anterior uveitis, kidney failure, proteinuria, and inflammatory syndrome, research of infectious agents or auto-immunity origin was negative. Renal biopsy showed TIN lesions in subacute stage; biopsy of the salivary glands showed stage III chronic lymphocytic sialadenitis without Sjogren syndrome or sarcoidosis. The patient received corticosteroid treatment.

Discussion: The presence of TIN, recurrent anterior uveitis, no notion of drug intake, response to corticosteroids and exclusion of other diagnoses leads to TINU syndrome. Positivity of Quantiferon is explained by the fact that TINU syndrome is associated with high serological markers in the absence of their corresponding diseases, and presence of chronic lymphocytic sialadenitis explained by these immunological disorders without Sjogren syndrome, Both patients remained well without recurrence of uveitis 2 and 6 years later respectively.

Conclusion: TINU syndrome is secondary to immunological disorders as evidenced interstitial infiltrate of the renal parenchyma, the inflammatory disease of the uvea and good response to corticosteroid therapy.

Keywords: Interstitial nephritis; Uveitis; Tubulointerstitial nephritis; Uveitis syndrome; Autoimmunity

\section{Introduction}

Acute tubulointerstitial nephritis (ATIN) is a renal disease restricted to tubules and interstitium that can cause acute and chronic renal failure [1]. It may be secondary to many systemic disorders or kidney and urinary tract damage, The causes of AIN usually fall within one of three general categories: drug induced; infection associated; and autoimmune mediated. The third category includes Sjogren's syndrome; lupus nephritis; and tubulointerstitial nephritis and uveitis (TINU) syndrome $[2,3]$.

TINU syndrome is a disorder characterized by a combination of idiopathic acute tubulointerstitial nephritis and uveitis $[4,5]$, Since it was first documented in 1975 [6,7], only a little more than 200 cases of TINU syndrome have been reported [8,9], with approximately $60 \%$ of cases occurring in children [6]. Most of the patients with TINU syndrome are adolescents and young women, with a median age at the onset of 15 (range 9 to 74 ) years and a 3:1 female-to-male predominance [2,7], but others found an older age group with a male predominance [9]. In the other hand, there are arguments suggesting that TINU is underdiagnosed and may be far more common than currently appreciated, especially in young patients in whom mild renal disease does not become symptomatic and/or if diagnostic tests regarding renal involvement are not performed at the time of presentation $[8,10]$.

TINU syndrome is regarded as a rare cause of acute tubulointerstitial nephritis (ATIN) [6], The pathogenesis of TINU is not clear, but it is thought to be the result of an autoimmune process that might involve humoral and cellular autoimmunity [2,11]. Renal tubular and ciliary body epithelia share some similar functions, such as those pertaining to electrolyte transporters sensitive to carbonic anhydrase inhibitors. Thus, it is conceivable that they might share cross-reactive autoantigens $[2,8,12]$. A recent study demonstrated the presence of autoantibodies recognizing a common autoantigen found in both tubular and uveal cells in the serum of a 15-year-old girl suffering from TINU syndrome [13]. However, an exact cross-reactive autoantigen in TINU syndrome has yet to be identified [2]. 
Citation: Laidoudi A, Hakem D, Ghout A, Boukrara A, Medaoud S, et al. (2016) Tubulointerstitial Nephritis and Uveitis (TINU) Syndrome, Two New Cases and Review of the Literature. J Nephrol Ther 6: 252. doi:10.4172/2161-0959.1000252

Page 2 of 11

The aim of this report is to describe 2 cases of TINU syndrome in 2 patients in whom immunological disorders created differential diagnostic difficulties.

\section{Case 1}

A 25 year old woman, nurse, with no medical history, no cardiovascular risk factor, she was taking no medication (no non steroid anti inflammatory drugs, no antibiotic...). In February 2014, she started to have nosebleeds with high blood pressure until 200/120 $\mathrm{mmHg}$, she was treated with Amlodipine $10 \mathrm{mg} / \mathrm{d}$, after she started to have edema of the lower limbs count on adverse effect of calcic inhibitors, so she switched to Irbisartan $150 \mathrm{mg} / \mathrm{d}$, her blood tests showed anemia $9.6 \mathrm{~g} / \mathrm{dl}$; elevated creatinine levels with estimated glomerular filtration rate (eGFR) at $26 \mathrm{ml} / \mathrm{mn} / \mathrm{m}^{2}$; proteinuria of 450 $\mathrm{mg} / \mathrm{d}$ and slight elevated erythrocyte sedimentation rate (ESR), echography of the kidney and Doppler of the renal arteries showed no abnormalities. On march, she experienced eye pain with redness, decreased visual acuity and photophobia, ophtalmological examination revealed an acute unilateral anterior uveitis, for which she received local treatment. 1 month later, she was referred to us and admitted to explore asthenia and weight loss of $6 \mathrm{Kg}$. Clinical examination revealed a blood pressure (BP) of 170/130 $\mathrm{mmHg}$ (severe hypertention); class II dyspnea (NYHA); a holosystolic heart murmur in the mitral area without heart failure signs, a mucocutaneous pallor but no signs of vasculitis, urine dipstick test finds traces of protein; hematuria and aciduria; ocular fundus exam found grade I hypertensive retinopathy, the rest of the examination was normal. Biological studies showed kidney failure with eGFR of $18.71 \mathrm{ml} / \mathrm{mn} / 1.73 \mathrm{~m}^{2}$; proteinuria was 540 $\mathrm{mg} / 24 \mathrm{~h}$; ESR of $37 \mathrm{~mm} /$ hour; polyclonal gammaglobulinemia (slightly elevated); urinary $\beta 2$ microglobulin was 47 times normal $(4.3 \mathrm{mg} / \mathrm{l}$ $(<1.8)$ ). Kidney biopsy with histological examination showed a non caseating granuloma in the interstitial tissue ( presence of rare hyaline casts in the kidney tubules, and tubulo-interstitial nephritis with granulomatous lesions in the medullary parenchyma). The patient received corticosteroid treatment (pulse IV followed by high-dose daily). Further exploration was done mainly oriented to sarcoidosis and tuberculosis and the other differential diagnosis was all negative but QuantiFERON was 10 times normal with negativity of all other examinations to koch's bacillus $(\mathrm{KB})$ : $\mathrm{TB}$ Skin test $=0.7 \mathrm{~mm}$; uricult was negative; angiotensin-converting enzyme at normal levels; chest and abdominal computed tomography scanning showing no abnormalities; bronchoscopy showed non specific inflammatory mucosa; bronchial aspirate no KB infection; multiples biopsies from the liver; bronchial mucosa; accessories salivary glands did not find any other sites of granulomas. Biological and imaging studies looking for a secondary cause and to evaluate her hypertension were negative. A TINU syndrome was highly suspected and confirmed after having ruled out most diagnosis that can cause both bipolar involvement. The patient responded well under corticosteroids (high-dose daily then gradually tapered off), but without normalization of the renal function. She untimely stopped treatment after 4 months which caused a relapse of her renal disease that required a $2^{\text {nd }}$ pulse corticosteroids then highdose daily. Corticosteroid-sparing was provided by mycophenolate mofetil (MMF). The patient remained well without recurrence of uveitis 2 years later but without complete recovery of renal function which improved gradually with immunosuppressive treatment (Figures 1 and 2).

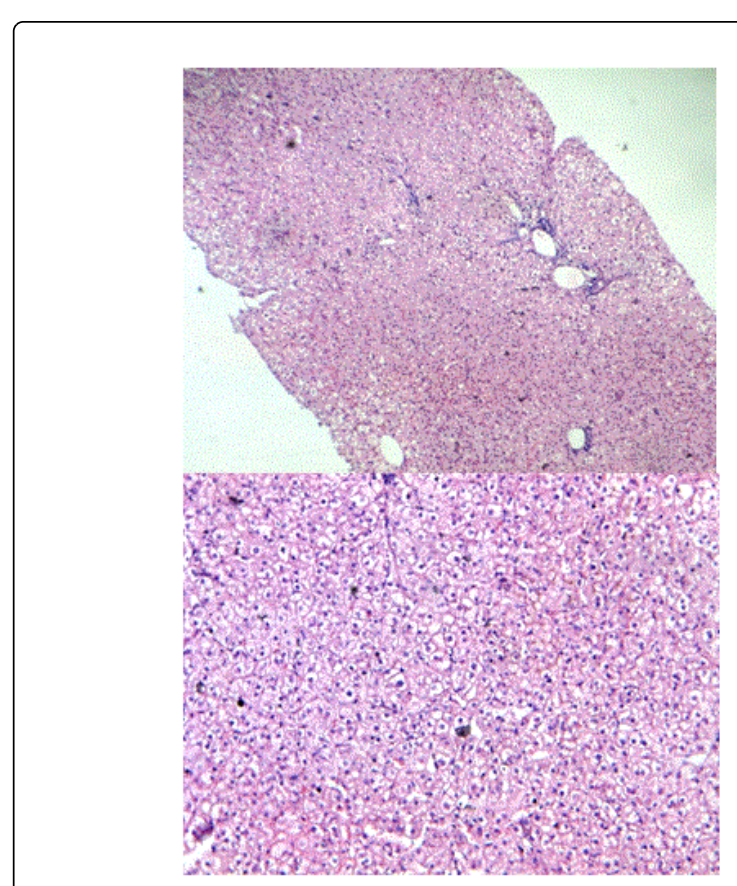

Figure 1: Biopsy specimen of the liver from patient. Hepatic parenchyma showed diffuse microvascular steatosis without granulomatous lesions.

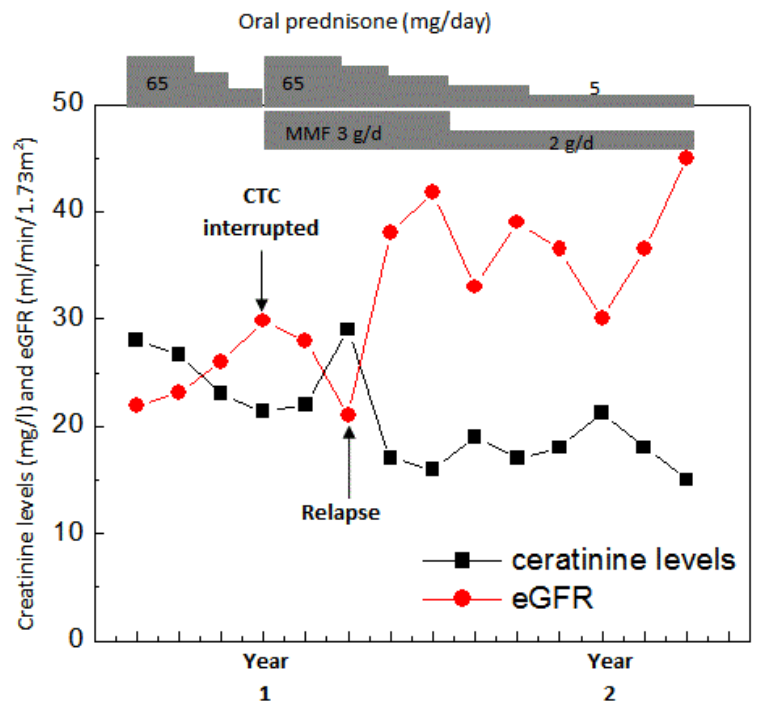

Figure 2: Course of creatinine levels and eGFR of patient 1 over a perod of 2 years.

\section{Case 2}

A 46 year old woman, professional lab, without specific personal history, but a mother who died of chronic kidney failure, presented 1 month before her admission a recurrent bilateral anterior uveitis for which she received a local treatment, and whose biological finding objective an increase in serum creatinine and positive CRP. The clinical 
examination was unremarkable, the urine dipstick showed proteinuria (+); glycosuria: traces; $\mathrm{pH}$ at 6; no leucocyturia; no hematuria; and no nitrites. Biological studies showed kidney failure with an eGFR of 14 $\mathrm{mL} / \mathrm{min} / 1.73 \mathrm{~m}^{2}$; inflammatory syndrome $(\mathrm{CRP}=58.8 \mathrm{mg} / \mathrm{l}$, fibrinogène $=5.5 \mathrm{~g} / \mathrm{l}$; serum protein electrophoresis: hyper alpha $2=$ $9.5 \mathrm{~g} / \mathrm{l}$, slight hypergammaglobulinemia of $14.1 \mathrm{~g} / \mathrm{l}$ ); proteinuria of 650 $\mathrm{mg} /$ day, research of infectious agents or auto-immunity origin was negative (ANA, ANCA, RF). Renal biopsy showed tubulointerstitial nephritis lesions in subacute stage : perivascular C3 deposition without glomerular deposition, vasculitis lesions or peritubular capillary alteration. Biopsy of the salivary glands showed stage III chronic lymphocytic sialadenitis (the Chisholm and Mason classification) without xerostomia, AntiSSA, antiSSB negative. Chest X-ray and abdominal-pelvic ultrasound were without abnormalities. Gallium scintigraphy did not find any signs suggesting a type of sarcoidosis inflammatory. The diagnosis of TINU syndrome was retained after exclusion of the other differential diagnosis. The patient received corticosteroid treatment $(1 \mathrm{mg} / \mathrm{kg} /$ day then gradually tapered off). Serum creatinine improved quickly with normalization 3 months later. The patient remained well without recurrence of the disease 7 years later and without any other extra-renal or extra-ocular symptom which can redress the diagnosis (Figures 2 and 3 ).

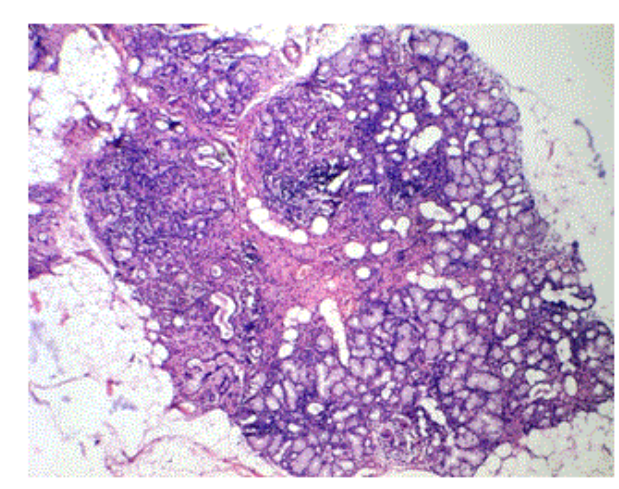

Figure 3: Biopsy of the salivary glands of patient 2: Disruption of normal lobular architecture by fibrosis and marked inflammatory infiltrate grouped in clusters, ductal metaplasia is observed. Conclusion: Stage III chronic lymphocytic sialadenitis (the Chisholm and Mason classification).

\section{Discussion}

In 1975, Dobrin et al. Described two adolescent females with acute eosinophilic tubulointerstitial nephritis; bilateral anterior uveitis; high ESR; hypergammaglobulinemia and bone marrow and lymph node granulomas [14]. In 1985, this disease was named tubulointerstitial nephritis and uveitis syndrome (TINU) syndrome by Grefer and Dusek et al. [15,16]. Most patients subsequently reported had a combination of TIN and uveitis without granulomas, and are presently included in TINU syndrome [17].

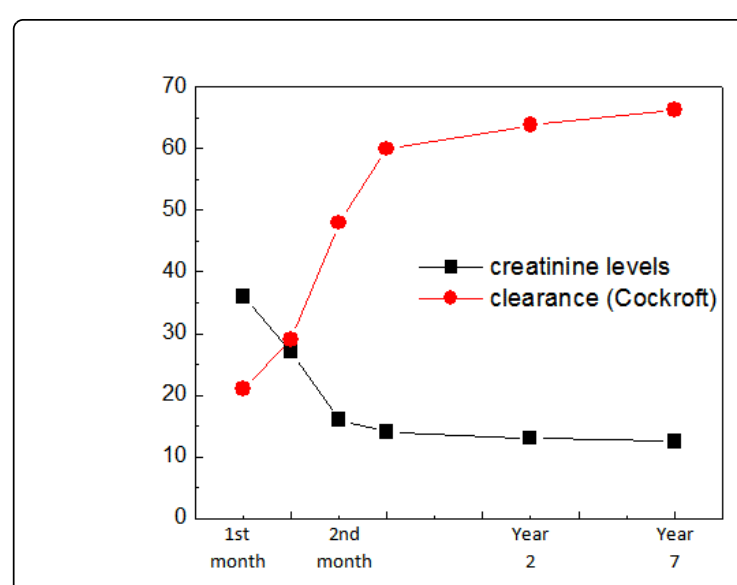

Figure 4: Course of creatinine levels and clearance of creatinine of patient 2 over a period of 7 years.

TINU syndrome is clearly rare, accounting for $2 \%$ or less of patients in university-based uveitis practices [5,9]. It is not always recognized and may be more common than previously thought in subsets of patients [9]. However, in Japan, TINU syndrome is the second most frequent diagnosis in children with uveitis after sarcoidosis [18]. The female predominance in reported cases of TINU syndrome (3:1 female to male ratio) is recently changing with an increasing number of reports of male patients in the more recent literature ( male patients constituted only $18 \%$ of patients reported prior to 1990 , but $34 \%$ of patients reported since 1990) [19]. This syndrome can appear at any age [20], however, most cases of TINU syndrome are reported in adolescents and young women [18]. It was diagnosed in $10 \%$ of individuals with bilateral anterior uveitis who were over age 20 , and one- third of the individuals younger than 20 years old [9]. The median age of onset reported since 1990 was 15 years (14years in males and 17 in females) [19]. Few reports have been in adults and the elderly [20], as in our second case. Thus, patient 2 is a rare case from an epidemiological viewpoint.

The pathogenesis of this disease remains unclear. The theories are varied and range from infection-related etiologies to primary cellular immune-mediated disease [21]. The most likely hypothesis is that the disease is an autoimmune disorder [17]. The association between acute interstitial nephritis and uveitis could either be due to a single primary disease process affecting both the kidney and the eye, or the eye could be secondarily inflamed as a result of immune reactions generated during the renal disease [19]. Renal tubular and ciliary body epithelia share several functions, including active electrolyte transport sensitive to carbonic anhydrase inhibitors. Thus, they may share closely related antigens that could account for cross-reactivity [19]. Lymphocytemediated immune mechanism to a common antigen present in the tubulointerstitium and uvea has been suggested, as reported in a unique case of particular interest presented by Abed et al. in which it adduces arguments for a pathophysiologic role of concomitant antiuveal and anti-renal tubule antibodies $[5,8,13,19,22]$. Specific basement membrane antigens have also been found to be immunogenic in animal models of acute interstitial nephritis, and only few patients with TINU were specifically reported to have immunofluorescent tubular basement membranes (TBMs) staining indicating antibody deposition $[8,11,23]$. It has been also reported a tubular depositions of complement components such as C3 and the C5b-9 complex [6]. On 
the other hand, TINU syndrome has sometimes been associated with polyclonal hypergammaglobulinemia and elevated serum immunoglobulin IgG levels suggesting a humoral mediated immune response [24], as in our tow patients. Serologic evidences of autoantibodies such as anti-nuclear antibody (ANA); anti-neutrophil cytoplasmic antibody (ANCA); anti-cardiolipin antibody (ACA); antitubular basement membrane antibody (ATBMA) and circulating immune complexes support also a disturbance in humoral-mediated immunity $[1,3,22,23,25,26]$. However, presence of autoantibodies does not necessarily indicate the presence of an autoimmune disease. As an example, natural anti-glomerular basement membrane autoantibodies exist in normal human sera $[8,23]$.

$\mathrm{T}$ cell-mediated immune response was found to be exaggerated. This is supported by reports of a decreased peripheral CD3+, CD4+ and $\mathrm{CD} 8+$ lymphocytes; decreased $\mathrm{CD} 4 / \mathrm{CD} 8$ ratio; an increased expression of $\mathrm{CD} 25$; the low-affinity receptor for interleukin-2 on $\mathrm{T}$ lymphocytes; higher circulating levels of soluble tumor necrosis factor receptor during the active stage of the disease; clinical anergy and dramatic response of renal disease to corticosteroids [19,22]. It has been postulated that T-cells are interleukin-2 receptor positive, suggesting they had been induced by antigen activation. The antigenic insult within the renal parenchyma could also attract an eosinophilic and mononuclear response, with concurrent activation of lymphatic and bone marrow histiocytes leading to the granuloma formation [21]. The possibility of a suppression of cellular immunity has also been suggested [15,19]. Thus, analogous to sarcoidosis, the systemic immune response may be suppressed, while locally there seems to be vigorous immune reactivity in the uvea and kidney. This depression of cellular immunity seems to be limited to the acute phase of the disease [21].

TINU syndrome does not appear to be associated with any racial or ethnic group. Race is not specifically mentioned in most reports [19]. However, The genetic role has to be determined because of the frequent and sometimes strong association with HLA phenotypes and the sequential development in monozygotic twins [22]. HLA associations can differ between populations. The most commonly reported HLA specificities have been HLA-A2 and HLA-A24. HLAA24 (or -A9) was identified in $75 \%$ of Japanese patients. A strong association with HLA-DR1, particularly in a North American and German patients has been reported. There were also HLA-DQ associations in some case reports. There have been subsequent reports of HLA typing in patients that imply the haplotype, and in particular the DQ alleles may be important [9]. Several HLA types such as DQ, Cw3, and DR6 have been previously noted as genetic factors in the cause of TINU syndrome [17]. However, the number of reported cases is insufficient for a statistical analysis to assess the relative risks associated with reported HLA specificities [19].

There have been no reports of multiple family members, familial TINU syndrome occurrence is quite rare. It has been reported in identical twins (boys or girls) and two pairs of sisters so far [27-29] and two generations of the same family [16] and no reports of geographic clustering of TINU syndrome cases $[19,30]$. This fact argues against either environmental or genetic factors as dominant influences in the pathogenesis of the disease [19].

Mandeville et al. reviewed 122 reported cases of TINU syndrome in which risk factors were addressed. Approximately half the cases of TINU syndrome (59 of 122) had no risk factor, and the disease was considered idiopathic [19,31]. In some reports, infection-triggered pathological immune reaction was suggested to play a role in the pathogenesis of TINU syndrome [32]. However, infectious agent could not be found in most cases in the literature, although there have been reports of the association of TINU syndrome and toxoplasmosis, chlamydial and EBV infection [15]. In terms of medications, antibiotic use is the most commonly identified risk factor for the development of TINU syndrome followed by nonsteroidal anti-inflammatory drug (NSAID) use [9]. The use of the Chinese herb "Goreisan" was causally related to TINU syndrome [31].

An association with a hypoparathyroidism [33]; lymphoid interstitial lung disease with alveolitis [34]; hyperthyroidism [35]; Cogan's syndrome [36] and IgG 4 related syndrome [37] has been reported. There are few reports of patients with TINU syndrome who had family members suffering from autoimmune diseases, including a father with Vogt-Koyanagi-Harada syndrome and sister with ulcerative colitis. Because these associations have rarely been reported, is it a coincidence or it is possible that whatever immune dysregulation results in TINU syndrome can result in disease in different tissues? $[9,19]$.

Patients usually present with systemic signs including fatigue (28\%); malaise (44\%); anorexia (28\%); weight loss (47\%) and fever (53\%) $[9,15,19,26]$. Other, less common findings include: abdominal or flank pain $(28 \%)$; arthralgias or myalgias (17\%); and also anemic syndrome [9] Usually this phase is followed by renal symptoms of acute nonoliguric renal dysfunction.

Interstitial nephritis may occur with few or even no symptoms, to be found only when a high suspicion led to test blood and urine for evidence of interstitial nephritis [9]. In one case report, TINU syndrome presented with multiple proximal and distal tubular dysfunction including a complete type of Fanconi's syndrome [38]. Patients may present with nonspecific signs and symptoms of acute renal dysfunction. These may include the acute or subacute onset of nausea, vomiting, and malaise. Patients may be oliguric [39].

Acute anterior uveitis is a sign of an underlying systemic disorder [40,41]. Uveitis may be asymptomatic [21], The most common ocular complaints were eye pain and redness (77\%); decreased vision $(20 \%)$ and photophobia (14\%) [19]. Usually, uveitis manifests within weeks to months of the beginning of the nephritis (up to 14 months) (65\%) with a median time to onset of ocular symptoms of 3 months after the onset of systemic symptoms, but it may also precede the renal symptoms (rarely more than 2 months) (21\%) or developed concurrently with $(15 \%)[8,9,19,40,15]$. In most cases $(77 \%)$, bilateral uveitis is observed, limited to the anterior segment in $80 \%$ of cases. Anterior segment findings include anterior chamber cells and flare; conjunctival injection and keratic precipitates [19]. Posterior segment involvement is most commonly limited to vitritis, which may have been a "spillover" from the anterior uveitis in some cases. In some fiew case reports, ocular finding presented with optic nerve head edema or retinal vasculitis [9]. Overall uveitis cases, $50 \%$ or more have no identified cause, it may be considered "idiopathic uveitis" if the associated interstitial nephritis was asymptomatique or had resolved by the time the intraocular inflammation developed [19].

There are no specific serum markers or laboratory findings that are unique to patients with TINU syndrome [40-42], but In order to look for a specific blood test, Krebs Von Den Lunge-6 (KL6) and modified CRP (mCRP) antibodies were found to be elevated in patients with TINU syndrome.

Laboratory findings may typically revealed poor renal function, including elevated blood urea nitrogen (BUN) and serum creatinine 
levels. Sterile leukocyturia (55\%), glucosuria (47\%), predominantly tubular proteinuria $(86 \%)$, hematuria $(43 \%)$ and eosinophilia may also be observed, anaemia (96\%), slightly abnormal liver function tests and evidence of systemic inflammation : an elevated ESR (89\%) and CRP, elevated serum IgG levels were also obsrved with increase of polyclonal gamma globulin concentrations $[9,15,19,42]$.

Urinary beta-2 microglobulin (UB2M)levels, a marker for interstitial nephritis was found elevated. It is the last test on urinalysis to become normal and it may remain elevated for months after the routine urinalysis and serum creatinine have returned to normal, which may be helpful if the patient presents after the AIN has otherwise resolved or if TINU syndrome is suspected but the patient has few or no symptoms of AIN, this is interesting to retrospective diagnosis of patient with uveitis and a privious asymptomatic TIN $[9,19]$ and also to detect a relapse of TIN. In our patients, UB2M was not available in first time, it was done only for first patient when creatinine levels started to increase, it was found to be 47 times normal suggesting a kidney relapse.

Associations of TINU with a variety of serologic markers in the absence of their correspondent disease have been reported. Thus, the disorder has been associated with ANA, ANCA, antiGBM,...as montioned above, in our cases, there were no autoimmunity disorders and no clinical signs of systemic disease.

Serum Krebs von den Lunge-6 (KL-6) measurement is a novel and useful laboratory parameter for the management of patients with TINU syndrome. KL6 is a human glycoprotein secreted by type II alveolar cells in the lung, and its serum levels increase in patients with pneumonia of various causes, as well as ocular sarcoidosis. KL-6 may be released from renal tissues under certain pathological conditions. It is intresting to quantify in patients with TINU syndrome which has no pulmonary lesions, high KL-6 levels may reflect the renal lesion of TINU syndrome. Serum KL-6 may be a potential laboratory parameter for the diagnosis and follow-up of patients with TINU syndrome, that could complement urinary B2-microglobulin measurements [5].

mCRP is considered to be a tissue and/or cell-based form of the acute phase protein with less understood properties and biologic effects. It may be produced by various cells such as lymphocytes; smooth muscle cells and renal tubular epithelial cells. mCRP facilitates the safe clearance of damaged self-materials and can also protect against unwanted complement activation in the fluid phase, its levels decreased in remission. Autoantibodies against mCRP might interrupt its normal biologic functions and lead to excessive complement activation with persistent renal and ocular injury. The level of antimCRP autoantibodies in sera from patients with lupus nephritis was closely associated with the score of their interstitial lesions. Ying Tan presented a very interesting work by demonstration a high prevalence of serum anti-mCRP autoantibodies in renal and ocular tissues, by showing co-localization of mCRP and human IgG from all of the 9 patients with TINU syndrome studied (tubular epithelial cells, interstitia, and uveal cells). mCRP may be one of the common target autoantigens in renal and ocular tissues in patients with TINU syndrome [2].

The Quanti- FERON-TB Gold In-Tube (QFT) assay is a T-cellbased test which uses enzyme-linked immunosorbent assay to measure antigen-specific production of interferon- $\gamma$ (IFN- $\gamma$ ) by circulating $\mathrm{T}$ cells in whole blood. Pooled average specificity was $97.7 \%$ in QFT, and was unaffected by BCG vaccination [43,44]. Discordant positive QFT reactions and negative tuberculin skin test reactions occurred in $6 \%$ to $7 \%$ of all persons and accounted for $23 \%$ of all positive results [43]. The reasons for this discordance remain speculative, with possible explanations including greater variability in immunologic reactivity of effector versus central memory T cells. It is well known that IFN- $\gamma$ is secreted essentially by activated T cells, in case 1, positivity of QFT can be explained by a high secretion of IFN- $\gamma$ by activated T cells found in the renal biopsy specimen which characterize the histological finding of TNIU syndrome. IN our knowledge, this is the first time QFT was measured in a patient with TINU syndrome. Repeatability of this test is not valid, a second test performed on the same blood sample will typically be $19 \%$ greater than the initial test, for which we did not repeat the test for the patient [45].

\begin{tabular}{|c|c|c|c|c|c|c|}
\hline & First patient & & & & $\begin{array}{l}\text { Second } \\
\text { patient }\end{array}$ & \\
\hline & Acute phase & In remission & Relapse period & In remission & Acute phase & In remission \\
\hline Red blood cells $(\mathrm{m} / \mu \mathrm{l})$ & 4.91 & 3.74 & 4.55 & & 3.84 & 3.74 \\
\hline Hemoglobin (g/dl) & 11.7 & 11.8 & 12.5 & & 11.8 & 11.5 \\
\hline Hematocrit (\%) & 36.9 & 35.5 & 38.6 & 13 & 32.6 & 12.4 \\
\hline Platelets & 241000 & 312000 & 254000 & & & 370000 \\
\hline White blood cells $(103 / \mu l)$ & 6400 & 8300 & 8700 & & 10000 & 12400 \\
\hline Neutrophils (\%) & & 62.8 & 73.9 & & 72.7 & 65.4 \\
\hline Lymphocytes (\%) & & 31.5 & 21.2 & & 21 & 28.1 \\
\hline Erythrocyte sedimentation rate $(\mathrm{mm} / \mathrm{h})$ & 37 & 13 & 18 & & & \\
\hline $\operatorname{CRP}(\mathrm{mg} / \mathrm{l})$ & 1.4 & & 0.4 & & 51 & 8.7 \\
\hline Fibrinogen (g/l) & 3.51 & 3.71 & & & 4.76 & \\
\hline
\end{tabular}


Citation: Laidoudi A, Hakem D, Ghout A, Boukrara A, Medaoud S, et al. (2016) Tubulointerstitial Nephritis and Uveitis (TINU) Syndrome, Two New Cases and Review of the Literature. J Nephrol Ther 6: 252. doi:10.4172/2161-0959.1000252

Page 6 of 11

\begin{tabular}{|c|c|c|c|c|c|c|}
\hline Serum creatinine (mg/dl) & 32.1 & 18 & 29 & 15 & 28 & 13 \\
\hline GFR $\left(\mathrm{ml} / \mathrm{min}\right.$ per $\left.1.73 \mathrm{~m}^{2}\right)$ & 18.7 & & & & 0.48 & 0.42 \\
\hline Urea $(\mathrm{g} / \mathrm{l})$ & 0.53 & 0.37 & 1.07 & 0.37 & 41 & 31 \\
\hline Uric acid (mg/l) & & & & & 595 & 140 \\
\hline Proteinuria (g/24 h) & & 540 & 98 & & 76 & 68 \\
\hline Total protein $(\mathrm{g} / \mathrm{l})$ & 71 & & & & 34 & 40 \\
\hline Albuminemia (g/l) & 37.5 & & & & 14 & \\
\hline Gamma globulins (g/l) & 14.63 & & & & 14.15 & \\
\hline $\lg G$ & & & & & 3.51 & \\
\hline $\lg M$ & & & & & 4.21 & \\
\hline $\lg A$ & & & & & 3.72 & \\
\hline Kapa & & & & & 2.28 & \\
\hline lamb & 73.2 & 87.2 & 90.5 & & 94 & 91 \\
\hline Calcemia & 50.38 & & 46.21 & & 27 & 29 \\
\hline Phosphoremia & & & 35 & & 60 & 120 \\
\hline Serum iron $(\mu \mathrm{g} / \mathrm{dl})$ & 26 & & 19 & 14.1 & 24 & 23 \\
\hline ASAT & 25 & & 13 & 8.1 & 25 & 15 \\
\hline ALAT & 1.015 & 1.02 & & & 1.015 & \\
\hline Urine gravity & 5.5 & 7.5 & & & 6 & \\
\hline Urine $\mathrm{pH}$ & Absent & Absent & & & absent & \\
\hline Urine infection & 4.3 & & & & & \\
\hline Urine B2 microglobulin $(\mathrm{mg} / \mathrm{l})(<1.8)$ & & & & & & \\
\hline
\end{tabular}

Table 1: Evolution of blood and urine analysis during and after AIN.

The definite diagnosis of TINU syndrome requires a renal biopsy, and consistent with acute interstitial nephritis which is characterized by renal interstitial edema and infiltration by inflammatory cells with relative sparing of the glomerular and vascular structures on renal biopsy [9,42]. Renal tubulointerstitial infiltrates are composed of lymphocytes, plasma cells and activated macrophages. The majority of lymphocytes were found to be T-lymphocytes expressing IL-2 receptors, indicating an activated state [19], but eosinophils as well as neutrophils may also be found $(34 \%, 25 \%$ respectively) $[9,19,22]$.

In the majority of reported cases (85\%), imunofluorescence studies failed to show the presence of immunoglobulin or complement components in the kidney biopsy specimens. In some few other cases, there was immunoglobulin staining of renal tubules; glomeruli; or mesangium in some cases, and the presence of complement components in others [19]. Our second patient showed a perivascular C3 deposition without vasculitis lesions; peritubular capillary alteration or glomerular deposition, which is a rare case since only $15 \%$ showed positive staining [19]. C3 complement component contributes to interstitial injury more than to glomerular lesions, this is due to the fact that Kidney tissue is particularly vulnerable to complementmediated damage due to the low expression of complement regulatory proteins on glomerular and tubular cells [28]. Thus, this deposition argues in favor of an immune-mediated renal diseases and so reinforce the hypothesis of autoimmune origin of TINU syndrome.

Non caseating granulomas were found in a minority of biopsy specimens of the kidneys (13\%) but also in the liver and bone marrow [9], No granulomata were found to contain fungi or acid-fast bacilli on histological examination [19]. The first case showed granulomas lesions in the renal biopsy specimen, biopsies from other organs (liver, accessories salivary glands, bronchial mucosa) showed no other sites of granulomas.

Diagnostic criteria have been designed for research purposes, but it can serve as a guide for the clinician (Table 2), criteria are based on the likelihood of having TINU syndrome and categorized as "definite," "probable," or "possible" [19]. The diagnosis requires demonstrating AIN. The "gold standard" is a renal biopsy but not necessary if the clinical and biologic presentation is typical for AIN.

Uveitis is most typically a symptomatic bilateral anterior uveitis of sudden onset, but this is not required for the diagnosis. The onset of uveitis should be 2 months prior to the onset to 1 year following the onset of AIN. The clinician must have a high index of suspicion to 
Citation: Laidoudi A, Hakem D, Ghout A, Boukrara A, Medaoud S, et al. (2016) Tubulointerstitial Nephritis and Uveitis (TINU) Syndrome, Two New Cases and Review of the Literature. J Nephrol Ther 6: 252. doi:10.4172/2161-0959.1000252

Page 7 of 11

diagnose TINU syndrome, as the renal disease and uveitis may occur many months apart. A longer duration between the AIN and uveitis is possible but uncommon, raising possibility that the two processes are not connected.
TINU syndrome still a diagnosis of exclusion. Diseases known to cause both uveitis and interstitial nephritis must be ruled out to apply the diagnosic criteria, in particular sarcoidosis [19].

\begin{tabular}{|c|c|c|}
\hline I. Definite TINU & II. Probable TINU & III. Possible TINU \\
\hline $\begin{array}{l}\text { (A) Acute interstitial nephritis (AIN): by renal biopsy or if biopsy is not done but } \\
\text { clinical course and laboratory examinations including abnormal urinalysis and } \\
\text { renal function examinations are all consistent with AIN }\end{array}$ & $\begin{array}{l}\text { (A) AIN: by renal biopsy or laboratory findings and } \\
\text { clinical course }\end{array}$ & $\begin{array}{l}\text { (A) AIN: diagnosed by } \\
\text { laboratory findings and }\end{array}$ \\
\hline (B) Uveitis: typical bilateral anterior uveitis & $\begin{array}{l}\text { (B) Uveitis: atypical (not bilateral anterior uveitis) } \\
\text { Or } \\
\text { (A) AIN: diagnosed by laboratory findings and clinical } \\
\text { course but not all laboratory findings or clinical } \\
\text { course complete, consistent, or available } \\
\text { (B) Uveitis: typical bilateral anterior uveitis }\end{array}$ & $\begin{array}{l}\text { clinical course but not all } \\
\text { laboratory findings or } \\
\text { clinical course complete, } \\
\text { consistent, or available } \\
\text { (B) Uveitis: atypical uveitis } \\
\text { (not bilateral anterior uveitis) }\end{array}$ \\
\hline
\end{tabular}

Table 2: Diagnostic criteria for tubulointerstitial nephritis and uveitis (TINU) syndrome [19].

In our patients the clinical and histologic features of the TINU syndrome were similar to those in the cases described earlier, defined as "probable" for the first case and "definite" for the second case (Table 2). In addition to renal and ocular abnormalities, patient 1 showed various systemic symptoms such as anemia, fatigue, weight loss, anorexia, which were reported to have been accompanied by TINU syndrome, patient 2 did not presented systemic signs. Both patients developed non-oliguric renal failure. Blood pressure was normal during the entire course for case 2 but elevated in the first case for which the patient received 3 different antihypertensive medications to partially normalize blood pressure. Laboratory tests are listed in Table 1. During the follow up period, no additional ocular findings that are distinct from uveitis, and also no involvement of additional organs.

The differential diagnosis of interstitial nephritis occurring in association with ocular findings is broad. Many autoimmmune diseases should be considered which could also lead to a similar clinical features $[1,19,21]$ (Table 3 ) as well as infectious diseases (Table 4). Many other diseases can cause renal and eye damage (Table 5). Drug induced AIN should be ruled out, it is also difficult to distinguish patients with TINU syndrome and late-onset uveitis from those with drug-induced interstitial nephritis [42].

Sarcoidosis syndrome has similar findings and can be confused with TINU syndrome, making accurate diagnosis difficult in the absence of characteristic involvement of other organs. Some case reports show evidence that TINU syndrome resembles Sjögren syndrome. The presence of immunoglobulins in the tubular basement membrane and interstitial is highly suggestive of an immunological process of tubular damage similar to that seen in Sjögren syndrome, These patients had chronic sialoadenitis on salivary gland biopsy but no symptoms of dry mouth [21], as well, our second case have has stage III chronic sialadinitis. In Sjogren syndrome, diagnosis is based on the presence of some criteria, basically the sicca symptoms must be present, which is not the case. In addition, no antibodies were detected: negative results for anti SSA and anti SSB. Thus, the histological lesions were isolated without clinical manifestations or positive biological tests. Sjogren syndrome was far to be the real diagnosis.

In case 1 , quantiFERON was 10 times normal, which created a differential diagnostic difficulties with tuberculosis infection. We looked for KB: no clinical signs of tuberculosis, no concept of contagion, Bacillus Calmette Guerin (BCG) scar was present and tuberculin skin test was only $7 \mathrm{~mm}$ suggesting a BCG vaccination [46-49], negative results of uricult, imaging study with Chest and abdominal computed tomography scanning showed no lesions, bronchoscopy with bronchial aspirate did not find $\mathrm{KB}$, all results were negative. In addition, patient received immunosuppressive treatment and she improved her renal function. Tuberculosis was far to be the real diagnosis.

\begin{tabular}{|l|l|l|}
\hline Disaeses & Renal manifestations & Ocular manifestations \\
\hline Systemic lupus & $\begin{array}{l}\text { Proteinuria, haematuria, nephrotic or nephrotic syndrome, } \\
\text { renal insufficiency, hypertension, lupus } \\
\text { glomerulonephritis }\end{array}$ & $\begin{array}{l}\text { Retinal vasculitis, dysoric retinopathy, retinal haemorrhage, } \\
\text { anterior uveitis, papilloedaema, optic neuropathy, cranial } \\
\text { nerve palsies or central nervous system vasculitis, cortical } \\
\text { blindness }\end{array}$ \\
\hline Gougerot- Sjögren & $\begin{array}{l}\text { Tubulointerstitial nephritis, tubulopathy, hypercalciuria, } \\
\text { nephrocalcinosis, nephrogenic diabetes insipidus, renal } \\
\text { insufficiency, immune complex glomerulonephritis }\end{array}$ & Sicca syndrome \\
\hline Sarcoidosis & $\begin{array}{l}\text { Tubulointerstitial nephritis } \pm \text { granuloma, hypercalcaemia, } \\
\text { renal calculi, nephrocalcinosis, renal insufficiency }\end{array}$ & $\begin{array}{l}\text { Anterior and posterior uveitis, optic neuropathy retinal } \\
\text { periphlebitis, macular oedema, retinal neovascularization, }\end{array}$ \\
\hline
\end{tabular}


Citation: Laidoudi A, Hakem D, Ghout A, Boukrara A, Medaoud S, et al. (2016) Tubulointerstitial Nephritis and Uveitis (TINU) Syndrome, Two New Cases and Review of the Literature. J Nephrol Ther 6: 252. doi:10.4172/2161-0959.1000252

Page 8 of 11

\begin{tabular}{|l|l|l|}
\hline & $\begin{array}{l}\text { membranous nephropathy, proliferative or crescentic } \\
\text { glomerulonephritis, focal glomerulosclerosis }\end{array}$ & $\begin{array}{l}\text { granuloma formation in the retina, choroid, optic nerve or } \\
\text { lacrimal gland, secondary glaucoma, cataract formation }\end{array}$ \\
\hline Rhumatoid arthritis & Renal vasculitis, AA renal amyloidosis & Scleritis, sicca syndrome \\
\hline $\begin{array}{l}\text { Wegener's } \\
\text { granulomatosis }\end{array}$ & $\begin{array}{l}\text { Pauciimmune crescentic glomerulonephritis, renal } \\
\text { insufficiency, genitourinary aneurysms, papillary } \\
\text { necrosis, ureteral and prostatic involvement, } \\
\text { retroperitoneal fibrosis }\end{array}$ & $\begin{array}{l}\text { Orbital inflammatory pseudotumor, scleritis, episcleritis, } \\
\text { conjunctivitis, peripheral ulcerative keratitis, uveitis, optic } \\
\text { neuritis, retinal artery occlusion, cranial nerve palsies and } \\
\text { proptosis, conjunctival ulceration }\end{array}$ \\
\hline Behc,et's disease & $\begin{array}{l}\text { Renal AA amyloidosis, proliferative glomerulonephritis, } \\
\text { necrotizing vasculitis }\end{array}$ & $\begin{array}{l}\text { Non-granulomatous anterior uveitis, retinal vasculitis, vascular } \\
\text { occlusion and optic neuritis, neovascularization, paralytic } \\
\text { strabismus, vitreous hemorrhage, secondary cataracts and } \\
\text { glaucoma }\end{array}$ \\
\hline TINU syndrome & Tubulointerstitial nephritis & $\begin{array}{l}\text { Anterior uveitis, posterior synechiae, cataract and elevated } \\
\text { intraocular pressure }\end{array}$ \\
\hline
\end{tabular}

Table 3: Differential diagnosis for the TINU syndrome [8].

\begin{tabular}{|l|}
\hline Infectious agents \\
\hline Brucellosis \\
\hline Tuberculosis \\
\hline Herpes simplex virus \\
\hline Toxoplasmosis \\
\hline Cytomegalovirus \\
\hline Epstein-Barr virus \\
\hline Syphilis \\
\hline Chlamydia \\
\hline
\end{tabular}

Table 4: Causative infectious agents that can cause both AIN and uveitis and mimic TINU [21].

TINU syndrome is uncommon and only few patients have been treated in the same institution. In the absence of larger, controlled studies, it is difficult to assess the efficacy of treatment. Moreover, no prospective, randomized studies have addressed the efficacy of treatment for acute interstitial nephritis [19]. Treatment is based on retrospective case series with relatively small numbers and often short follow-up times [9].

Treatment of the ocular and renal inflammation is approached like any form of noninfectious uveitis or AIN. Systemic corticosteroids are generally reserved for cases of progressive renal failure. Whether steroid therapy is required for the recovery of TIN is unknown. In previous studies, some patients received oral steroids to treat the renal insufficiency, and the response was favorable. However, some pediatric and adult patients were reported to recover spontaneously without using any drugs including steroids. Our patients were treated with systemic steroids because of the renal insufficiency [9].

In term of uveitis treatment, topical corticosteroids may be sufficient for anterior uveitis. But oral; periocular or even intravitreal corticosteroids may be required for posterior segment involvement.

The use of steroid-sparing immunomodulatory agents has been reported in chronic disease [9]. Immunomodulatory agents such as azathioprine; methotrexate; cyclosporine and mycophenolate mofetil (MMF) were used to treat uveitis if there is no response or if there is contra indication for systemic corticosteroids [19,22], and also they are promising to treat the refractory uveitis of TINU syndrome. The potential renal and hepatic toxicity should be concerned in patients who may already have active renal or hepatic inflammation [19]. MMF appears to be a useful alternative treatment for patients with steroidresistant or steroid intolerant AIN, and might be considered a good first-line option in patients for whom steroid treatment is undesirable such as obesity; diabetes or hypertension [48]. Our first case presented with grade I hypertension and with steroid resistance, she received 3 $\mathrm{g} /$ day MMF, she improved her renal function up to $46 \mathrm{ml} / \mathrm{mn} / \mathrm{m}^{2}$.

The follow-up period after the diagnosis of TINU syndrome was 26 months for the $1^{\text {st }}$ patient and 96 months for the second.

Creatinine clearance recovered to the normal range $(60 \mathrm{~mL} / \mathrm{min} /$ $1.73 \mathrm{~m}^{2}$ ) within 2 months for the second patient, however, the other patient showed creatinine levels up to $15 \mathrm{mg} / \mathrm{l}$ and. Urinary B2microglobulin excretion was elevated and she relapsed once during the follow up period.

Ocular symptoms generally resolved within 1 month without recurring in the 2 patients and During the followup, no patients were diagnosed as having systemic diseases or infectious pathology.

As a suggested scenario in acute TIN, three evolving phases (the first reactive phase, the second regulatory phase and the final healing phase) also could be considered in the evolution of idiopathic TINU syndrome. Spontaneous recovery of TIN in some idiopathic TINU syndromes indirectly suggests the successful regulatory and healing mechanism [22].

Recurrences of uveitis were common, having occurred in $41 \%$ of cases [19]. It has been described even after 10 years [30]. 52\% of these patients were reported to have a single recurrence, while 17 (33\%) had two or more recurrences and $15 \%$ had a prolonged course of uveitis with multiple exacerbations [19]. Younger patients (less than 20 years of age) were more likely to have a chronic course of uveitis (persistent inflammation lasting greater than 3 months) than older patients $(23 \%$ 
Citation: Laidoudi A, Hakem D, Ghout A, Boukrara A, Medaoud S, et al. (2016) Tubulointerstitial Nephritis and Uveitis (TINU) Syndrome, Two New Cases and Review of the Literature. J Nephrol Ther 6: 252. doi:10.4172/2161-0959.1000252

Page 9 of 11

versus $4 \%$, respectively), whereas younger patients were less likely to have recurrences of uveitis than older patients (35\% versus $49 \%$ respectively) [19].

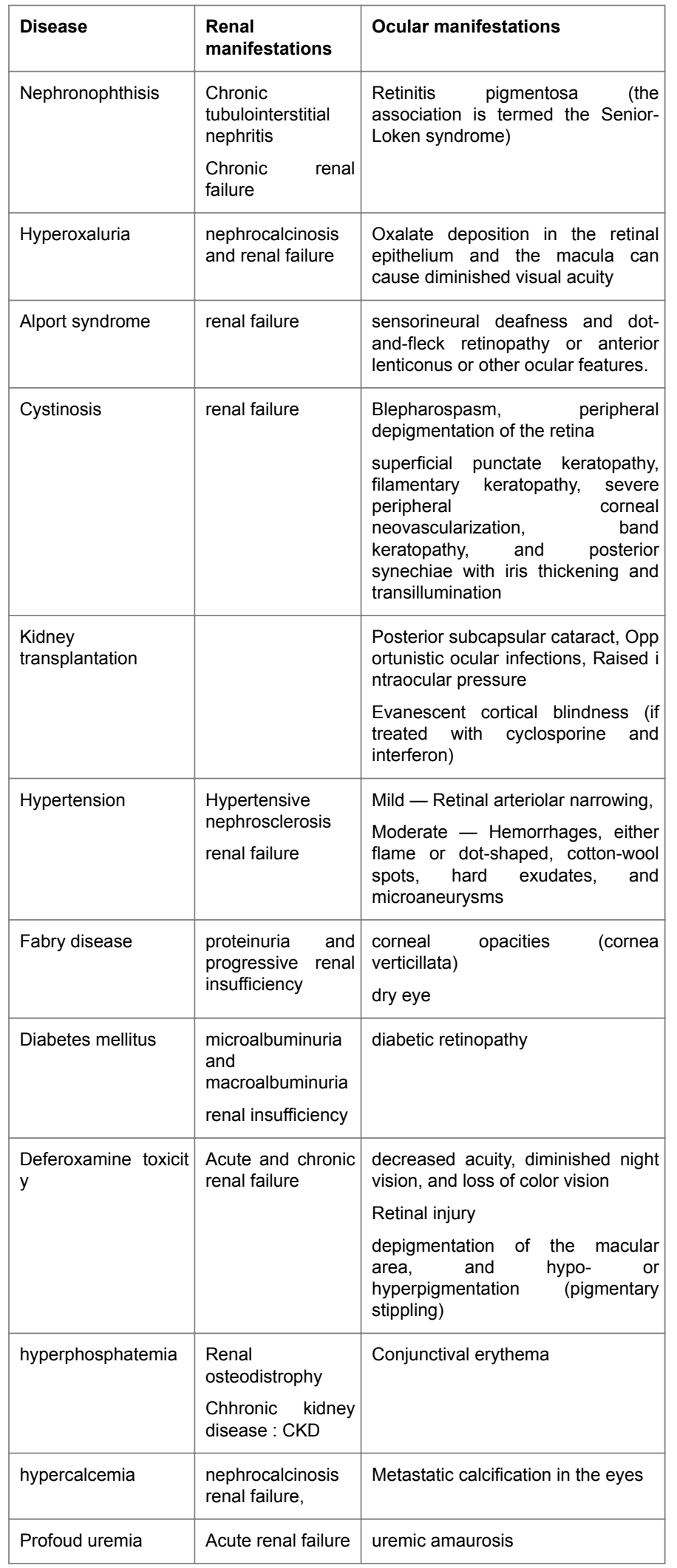

\begin{tabular}{|l|l|l|}
\hline $\begin{array}{l}\text { chronic } \\
\text { hypocalcemia }\end{array}$ & $\begin{array}{l}\text { asymptomatic } \\
\text { renal failure }\end{array}$ & posterior subcapsular cataracts \\
\hline $\begin{array}{l}\text { dot-and-fleck } \\
\text { retinopathy }\end{array}$ & renal failure & Retinopathy and anterior lenticonus \\
\hline Pingueculae & Renal failure & eye erythema \\
\hline $\begin{array}{l}\text { Age-related macular } \\
\text { degeneration }\end{array}$ & CKD & $\begin{array}{l}\text { age-related macular degeneration } \\
\text { (AMD) }\end{array}$ \\
\hline
\end{tabular}

Table 5: Causes of bipolar involvement (kidney and eye) [46,47].

Renal involvement is generally believed to be self-limited. TIN was reported with acute favorable course and uveitis with a chronic relapsing course $[15,22,26]$. In general, the renal disease tends to resolve either spontaneously or with corticosteroids $[8,9,15]$. Few cases were characterized by the recurrence of acute interstitial nephritis, as in case 1. Persistent renal dysfunction has been reported in $11 \%$ of cases, including several patients who required transient dialysis for a period of time (2 weeks to 5 months) [8].

The histological grade of tubulointerstitial lesions, creatinine clearance, or urinary B2-microglobulin levels was not related to the severity of uveitis, need for oral steroids, or recurrence of uveitis [17]. Although the visual prognosis generally is good. Many patients (56\%) develop chronic inflammation [5], complication commonly reported have been described in one-fifth of cases including the formation of posterior synechiae (68\%); swelling of the optic disk; cystoid macular edema; macular pucker and chorioretinal scar formation and ocular complications related to treatment with systemic corticosteroids $[8,19]$. Interestingly, uveitis seemed to be more severe when it recurred [9].

\section{Conclusion}

TINU syndrome is a rare entity with unknown pathogenesis, its association with autoimmune diseases suggests its autoimmune origin. TINU syndrome is secondary to immunological disorders as evidenced interstitial infiltrate of the renal parenchyma; the inflammatory disease of the uvea and good response to corticosteroid therapy. Some diseases have similar findings and can be confused with TINU syndrome, making accurate diagnosis difficult in the absence of characteristic involvement of other organs. Early diagnosis of TINU syndrome is challenging in patients with non-specific symptoms and laboratory findings. It should be emphasized that it is important to pay attention to ocular signs such as eye pain or redness. In addition, measurement of UB2M is essential for early diagnosis of TINU syndrome.

\section{References}

1. Simon AH, Alves-Filho G, Ribeiro-Alves MA (1996) Acute tubulointerstitial nephritis and uveitis with antineutrophil cytoplasmic antibody. Am J Kidney Dis 28: 124-127.

2. Tan Y, Yu F, Qu Z, Su T, Xing GQ, et al. (2011) Modified C-reactive protein might be a target autoantigen of TINU syndrome. Clin J Am Soc Nephrol 6: 93-100.

3. Gianviti A, Greco M, Barsotti P, Rizzoni G (1994) Acute tubulointerstitial nephritis occurring with 1-year lapse in identical twins. PediatrNephrol; 8:427.

4. Rosenbaum JT (1988) Bilateral anterior uveitis and interstitial nephritis. Am J Ophthalmol 105: 534-537.

5. Kase S, Kitaichi N, Namba K, Miyazaki A, Yoshida K, et al. (2006) Elevation of serum Krebs von den Lunge- 6 levels in patients with 
tubulointerstitial nephritis and uveitis syndrome. Am J Kidney Dis 48 935-941.

6. $\quad$ Li C, Su T, Chu R, Li X, Yang L (2014) Tubulointerstitial nephritis with uveitis in Chinese adults. Clin J Am Soc Nephrol 9: 21-28.

7. Litwin M, Michalkiewicz J, Jarmuzek W, Wo'zniewicz B, Grenda B, et al. (2002) Tubulointerstitial nephritis with uveitis: clinico-pathological and immunological study. Pediatr Nephrol 17: 683-688.

8. Izzedine $\mathrm{H}$ (2008) Tubulointerstitial nephritis and uveitis syndrome (TINU): a step forward to understanding an elusive oculorenal syndrome. Nephrol Dial Transplant 23: 1095-1097.

9. Levinson $\mathrm{RD}$ (2008) Tubulointerstitial nephritis and uveitis syndrome. Int Ophthalmol Clin 48: 51-59.

10. Mackensen F, Smith JR, Rosenbaum JT (2007) Enhanced recognition, treatment, and prognosis of tubulointerstitial nephritis and uveitis syndrome. Ophthalmology 114: 995-999.

11. Yoshioka K, Takemura T, Kanasaki M, Akano N, Maki S (1991) Acute interstitial nephritis and uveitis syndrome: activated immune cell infiltration in the kidney. Pediatr Nephrol 5: 232-234.

12. Sugimoto T, Tanaka Y, Morita $\mathrm{Y}$, Kume $\mathrm{S}$, Uzu T, et al. (2008) Is Tubulointerstitial Nephritis And Uveitis Syndrome Associated With Igg4Related Systemic Disease. Journal Compilation Asian Pacific Society Of Nephrology.

13. Abed L, Merouani A, Haddad E, Benoit G, Oligny LL, et al. (2008) Presence of autoantibodies against tubular and uveal cells in a patient with tubulointerstitial nephritis and uveitis (TINU) syndrome. Nephrol Dial Transplant 23: 1452-1455.

14. Dobrin RS, Vernier RL, Fish AL (1975) Acute eosinophilic interstitial nephritis and renal failure with bone marrow-lymph node granulomas and anterior uveitis. A new syndrome. Am J Med 59: 325.

15. Grefer J, Santer R, Ankermann T, Faul S, Nölle B, et al. (1999) Tubulointerstitial nephritis and uveitis in association with Epstein-Barr virus infection. Pediatr Nephrol 13: 336-339.

16. Dusek J, Urbanova I, Stejskal J, Seeman T, Vondrak K, et al. (2008) Tubulointerstitial nephritis and uveitis syndrome in a mother and her son. Pediatr Nephrol 23: 2091-2093.

17. Takemura T, Okada M, Hino S, Fukushima K, Yamamoto S, et al. (1999) Course and outcome of tubulointerstitial nephritis and uveitis syndrome. Am J Kidney Dis 34: 1016-1021.

18. Goda C, Kotake S, Ichiishi A, Namba K, Kitaichi N, et al. (2005) Clinical features in tubulointerstitial nephritis and uveitis (TINU) syndrome. Am J Ophthalmol 140: 637-641.

19. Mandeville JT1, Levinson RD, Holland GN (2001) The tubulointerstitial nephritis and uveitis syndrome. Surv Ophthalmol 46: 195-208.

20. Salu P, Stempels N, Vanden Houte K, Verbeelen D (1990) Acute tubulointerstitial nephritis and uveitis syndrome in the elderly. $\mathrm{Br} \mathrm{J}$ Ophthalmol 74: 53-55.

21. Vohra S, Eddy A, Levin AV, Taylor G, Laxer RM (1999) Tubulointerstitial nephritis and uveitis in children and adolescents. Four new cases and a review of the literature. Pediatr Nephrol 13: 426-432.

22. Lee JW, Kim HJ, Sung SH, Lee SJ (2005) A case of tubulointerstitial nephritis and uveitis syndrome with severe immunologic dysregulation. Pediatr Nephrol 20: 1805-1808.

23. Z Cui, H-y Wang and M-h Zhao (2006) Natural autoantibodies against glomerular basement membrane exist in normal human sera.Kidney International 69: 894-899.

24. Wakaki H, Sakamoto H, Awazu M (2001) Tubulointerstitial nephritis and uveitis syndrome with autoantibody directed to renal tubular cells. Pediatrics 107: 1443-1446.

25. Tanaka H, Suzuki K, Tateyama TNT, Waga S, Ito E (2001) Repeat renal biopsy in a girl with tubulointerstitial nephritis and uveitis syndrome, Pediatr Nephrol 16: 885-887.

26. Gion N, Stavrou P, Foster CS (2000) Immunomodulatory therapy for chronic tubulointerstitial nephritis-associated uveitis. Am J Ophthalmol 129: 764-768
27. Morino M, Inami K, Kobayashi T, Yanagisawa K, Maeda K (1991) Acute tubulointerstitial nephritis in two siblings and concomitant uveitis in one. Acta Paediatr Jpn 33: 93-98.

28. Vaculik C, Rüger B M ,Yanagida G, Hollemann D, Soleiman A, Losert U M, Chen J et al Fischer M B (2008) Shift of C3 deposition from localization in the glomerulus into the tubulo-interstitial compartment in the absence of secreted IgM in immune complex glomerulonephritis, Clin Exp Immunol. Jan; 151(1): 146-154.

29. Tanaka H, Waga S, Nakahata T, Suzuki K, Ito T, et al. (2001) Tubulointerstitial nephritis and uveitis syndrome in two siblings. Tohoku J Exp Med 194: 71-74.

30. Thomassen VH, Ring T, Thaarup J, Baggesen K (2009) Tubulointerstitial nephritis and uveitis (TINU) syndrome: a case report and review of the literature. Acta Ophthalmol 87: 676-679.

31. Suzuki H, Yoshioka K, Miyano M, Maeda I, Yamagami K, et al. (2009) Tubulointerstitial nephritis and uveitis (TINU) syndrome caused by the Chinese herb "Goreisan". Clin Exp Nephrol 13: 73-76.

32. Kai WW, Donald JD, Thomas R, Hedges III, Soong HK, Robert TS et al Kenneth R (1987) Ocular Involvement Associated With Chronic EpsteinBarr Virus Disease.arch ophthal mol- Vol 105.

33. Catalano C, Harris PE, Enia G, Postorino M, Martorano C, et al. (1989) Acute interstitial nephritis associated with uveitis and primary hypoparathyroidism. Am J Kidney Dis 14: 317-318.

34. Hofmann N, Müller KM, Morath C, Waldherr R, Zeier M, et al. (2006) Lymphoid interstitial lung disease in a patient with acute tubulointerstitial nephritis and uveitis: a new facet of a rare syndrome? Am J Kidney Dis 47: e55-59.

35. Ebihara I, Hirayama K, Usui J, Seki M, Higuchi F, et al. (2006) Tubulointerstitial nephritis and uveitis syndrome associated with hyperthyroidism. Clin Exp Nephrol 10: 216-221.

36. Brogan K, Eleftheriou D, Rajput K, Edelsten C, Sebire NJ, Brogan PA (2012) Tubulointerstitial nephritis, uveitis, hearing loss and vestibular failure: TINUatypical Cogan's overlap syndrome. Rheumatology (Oxford) 51(5): 950-952.

37. Yoneda K, Murata K, Katayama K, Ishikawa E, Fuke H, et al. (2007) Tubulointerstitial nephritis associated with IgG4-related autoimmune disease. Am J Kidney Dis 50: 455-462.

38. Igarashi T, Kawato H, Kamoshita S (1992) Acute tubulointerstitial nephritis with uveitis syndrome presenting as multiple tubular dysfunction including Fanconi's syndrome. Pediatr Nephrol 6: 547-549.

39. Praga M, Appel GB, Palevsky PM Editor Alice M SheridanClinical manifestations and diagnosis of acute interstitial nephritis, http:// www.uptodate.com/contents/clinical-manifestations-and-diagnosis-ofacute-interstitial nephritis?source=search_result\&search=Clinical + manifestations+and+diagnosis+of+acute+interstitial + nephritis\&selectedTitle $=1 \sim 85$.

40. Birnbacher R, Balzar E, Aufricht C, Schmaldienst S, Woloszczuk W, et al. (1995) Tubulointerstitial nephritis and uveitis: an immunological disorder? Pediatr Nephrol 9: 193-195.

41. Stupp R, Mihatsch MJ, Matter L, Streuli RA (1990) Acute tubulointerstitial nephritis with uveitis (TINU syndrome) in a patient with serologic evidence for Chlamydia infection. Klin Wochenschr 68: 971-975.

42. Villalba NL, Marrero Robayna S, Ramírez Medina D, Moreno Casas S, Rodríguez Pérez JC(2014) Uveitis and Acute Interstitial Nephritis. What to Expect EJCRIM.

43. Menzies D, Pai M, Comstock G (2007) Meta-analysis: new tests for the diagnosis of latent tuberculosis infection: areas of uncertainty and recommendations for research. Ann Intern Med 146: 340-354.

44. Zwerling A, van den Hof S, Scholten J, Cobelens F, Menzies D, et al. (2012) Interferon-gamma release assays for tuberculosis screening of healthcare workers: a systematic review. Thorax 67: 62-70.

45. John ZM, Adithya C, Charles EM, Justin DL, Ngan PH, AND Edward AG (2013) Test variability of the quantiferon-tb gold in-tube assay in clinical practice. American journal of respiratory and critical care medicine vol 187. 
Citation: Laidoudi A, Hakem D, Ghout A, Boukrara A, Medaoud S, et al. (2016) Tubulointerstitial Nephritis and Uveitis (TINU) Syndrome, Two New Cases and Review of the Literature. J Nephrol Ther 6: 252. doi:10.4172/2161-0959.1000252

Page 11 of 11

46. Friedman EA, S Berns JS, Trobe J, Sheridan AM (2010) Eye disorders associated with chronic kidney disease.

47. Grunwald JE, Alexander J, Maguire M, Whittock R, Parker C, et al. (2010) Prevalence of ocular fundus pathology in patients with chronic kidney disease. Clin J Am Soc Nephrol 5: 867-873.
48. Preddie DC, Markowitz GS, Radhakrishnan J, Nickolas TL, D'Agati VD, et al. (2006) Mycophenolate mofetil for the treatment of interstitial nephritis. Clin J Am Soc Nephrol 1: 718-722.

49. Lutte M (2011) Antituberculeuse, Programme National de Lutte Contre la Tuberculose, Algérie. 